\title{
TOMÁS DE AQUINO Y LAS CINCO VÍAS DE LA EXISTENCIA DE DIOS Reflexiones sobre su vida y pensamiento filosófico-teológico
}

\author{
THOMAS AQUINAS AND THE FIVE WAYS TO THE EXISTENCE OF GOD \\ Reflections about his life and his theological and philosophical thought
}

Iván Maurial

\section{RESUMEN}

En este artículo que trata acerca de la probable existencia de un ser absoluto, se presentan, a modo de escenario, algunos aspectos importantes de la vida y de la obra de Tomás de Aquino. La primera intención de ello es dar a conocer la singularidad de su obra teniendo en cuenta su historia personal junto al contexto histórico e ideológico en el cual se desenvuelve el santo dominico. La segunda intención, que considero la más importante, es dar cuenta de la riqueza filosófica de la teología tomista, culmen del pensamiento medieval, a partir de la reflexión acerca de las cinco vías que argumentan sobre la existencia de Dios.

\section{Palabras clave}

Existencia de Dios, filosofía medieval, filosofía tomista, las cinco vías, Suma teológica

\section{ABSTRACT}

In this article, a brief vision of the life and philosophy of Thomas Aquinas is introduced in three general steps. Our first intent is to make known the peculiarites of his work considering his personal history along with the historical and ideological context in which the Dominican saint lived. The second purpose, which I believe is the most important, is to speak out about the philosophical richness of the Thomist theology, peak of the medieval thought, from the reflections on the five ways that substantiate the existence of God.

\section{Keywords}

Existence of God, medieval philosophy, Thomistic philosophy, the five ways, the Summa Theologica

\section{Vida de Tomás de Aquino}

Acerca de la vida del aquinate nos serviremos de las referencias de autores como Thai-Hop (1988), Copleston (1994), Fishl (1984), Fraile (2005), Guerrero (1996) junto a Llorca, García-Villoslada, Laboa, J. M. (2009), Reale, G. y Antiseri, D. (2010). Tomás nació en Aquino, castillo de Roccasecca cerca de
Nápoles en 1225. Su pensamiento tuvo a Dios como tema central. Sin embargo, valoró debidamente la experiencia sensible y el poder de la razón, mostrando su filosofía notoria tendencia hacia lo concreto. Su obra es uno de los momentos culminantes del pensamiento medieval, realizando la síntesis más acabada del aristotelismo y de la doctrina cristiana.

1 Licenciado en Psicología. Maestrista en Filosofía en la Universidad Nacional Mayor de San Marcos (UNMSM) y Docente de Estructura y Evaluación de la Personalidad en la Universidad Femenina del Sagrado Corazón (UNIFÉ). 


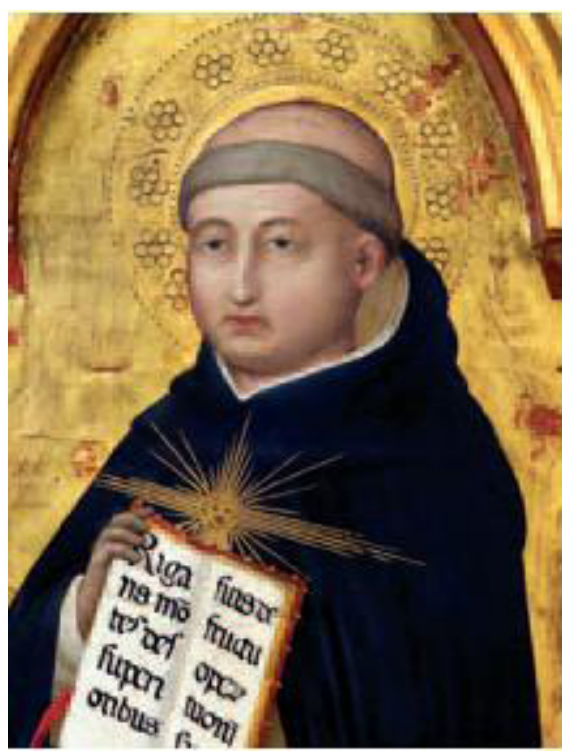

Santo Tomás de Aquino por Fra Angélico. Museo de San Marcos (Florencia, Italia).

Sus padres pertenecieron a la nobleza. Tenían la expectativa de un hijo que realizara la carrera eclesiástica y, de ese modo, asegurar la fortuna de la familia. Tomás de Aquino tuvo seis hermanos y cinco hermanas. A los cinco años es enviado a la abadía benedictina de Montecassino. Estudió con los monjes hasta los 14 años (1239) cuando el emperador Federico II expulsó a los religiosos de la abadía. A los pocos meses regresó a la Universidad de Nápoles donde se formó en filosofía y por la cercanía a un convento dominico se familiariza con frailes de la Orden Predicadores. A los 19 años, ingresa en la Orden, hecho que disgustó a su familia que se opuso sin poder persuadirlo de que se retire. En la Navidad de 1243 muere su padre. En 1244, el General de los Dominicos toma la decisión de llevárselo a Boloña para evitar el acoso de los familiares. Su madre envía a sus hermanos para raptarlo en el camino y es mantenido cautivo por su familia hasta que cambie de opinión. La prisión familiar duró un año. En 1245, con ayuda de sus hermanas, Tomás logró escapar de las murallas del castillo de Roccasecca (Aquino) para emprender camino a Nápoles en caballo junto al Director espiritual de los dominicos, fray Juan de San Julián.

Luego de su noviciado fue enviado a Colonia donde estudia teología junto a Alberto Magno (1193-1280) desde 1248 hasta 1251.
Ordenado sacerdote en 1252 y aún bajo la dirección de Alberto Magno, adquiere el título de Magíster. Ejerce la docencia en la Universidad de París. Allí también enseñaban los franciscanos, quienes junto a él se ganaron la preferencia de los estudiantes. Los profesores seglares se encontraban muy incómodos porque la aceptación que gozaban los profesores religiosos afectaba a sus cátedras. Ellos, por envidia, lograron que los frailes fueran amenazados para dejar de enseñar. Si asistían eran apedreados y necesitaron por un tiempo acudir con resguardo para no ser atacados.

El ataque del profesorado seglar no se detuvo en la fuerza física sino que recurrió a la difamación. Escribieron un libelo injurioso contra el papado a nombre de los monjes para desacreditarlos ante Roma. Luego se descubrió que los escritos pertenecían a los detractores. Buenaventura, Tomás de York y Tomás de Aquino defendieron vivamente su postura y refutaron a quienes los estaban difamando. En 1256 el Papa Alejandro IV puso orden y desterró al detractor. Restituyó a Buenaventura y a Tomás de Aquino en la Universidad. Tomás de Aquino fue designado Predicador General del Capítulo en Nápoles y Teólogo Consultor del Papa.

Escribió y publicó comentarios bíblicos y filosóficos, acerca de las Sentencias de Pedro Lombardo, sobre Boecio, en total 130 obras, 890 lecciones sobre Aristóteles, 1.650 comentarios acerca de las Sagradas Escrituras y 3.000 artículos acerca de otros temas. Sus obras más conocidas son la Suma contra los gentiles y la Suma Teológica. Santo Tomás además aportó en el ámbito metodológico al dejar atrás el estilo abrumador de las auctoritas donde el lector (profesor) daba lecciones desde los grandes compendios. Él prefirió los Comentarios literales según el estilo de Averroes (Martínez Lorca, 2011) que luego popularizó.

Tomás de Aquino escribe acerca de las cinco pruebas de la existencia de Diosentendido como un creador increado al que se puede acceder por la vía racional. Durante los siglos XII y XIII se escribieron numerosas sumas de teología 
que eran explicaciones completas y ordenadas de la doctrina católica. Aquella teología estaba centrada en temas como la redención, el cuerpo místico y las obras y señales de Dios. El fundamento de los temas expuestos era confiado íntegramente a la Sagrada Escritura. Tomás de Aquino decía que esos temas solo trataban acerca de manifestaciones de la divinidad y que la teología sólo se ocupaba de Dios mismo. La teología del aquinate, en cambio, se mueve dentro del ámbito la fe, pero además cuenta con el instrumental de la razón que busca dar cuenta de la naturaleza de los dogmas. En Occidente se conservó la lógica aristotélica y Tomás de Aquino pensó que era necesario corregirla y depurarla de su concepción pagana de Dios en beneficio del pensamiento cristiano.

En consonancia con la orientación temática que imprime el autor en la Suma Teológica cada artículo consta de cuatro partes:

1. Cuaestio: se plantea el problema de forma concisa: Se pregunta acerca de la existencia de Dios.

2. Disputatio: se exponen los argumentos a favor $y$ en contra: Expone las objeciones a la posibilidad de su existencia de Dios y la propuesta a favor de su existencia.

3. Responsio: solución razonada y justificada: Efectúa un razonamiento cuya conclusión niega los argumentos, en este caso en contra, de la existencia de Dios.

4. Vera solutio: vuelve sobre los argumentos expuestos en la disputatio para refutar las soluciones falsas y dar soluciones definitivas: Contesta a razonamientos que objetarían la existencia de Dios.

En 1269 Tomás de Aquino tiene a su cargo la docencia universitaria de teología para extranjeros. La situación se torna crítica. Los profesores seglares se oponen junto a los averroístas latinos de la mano de Siger de Brabant (1240 - 1285) a su aristotelismo radical. La filosofía aristotélica inicialmente había sido traducida al latín en función de la versión árabe. Tomás pide a dominico y helenista Guillermo de Moerbeke (1215 - 1286) que traduzca del griego lo más fiel posible las obras de Aristóteles y revise algunas otras ya traducidas. De Moeberke le proporcionó varias obras del estagirita traducidas desde su lengua original. Pero en el seno del clero había animadversión ideológica contra el peligro que suponía la interferencia del nuevo pensamiento filosófico en la creencia religiosa. Por ese motivo, los intelectuales franciscanos se unieron a los profesores seglares para condenar el aristotelismo, como veremos cuando revisemos las implicancias ideológicas del pensamiento tomista en el asunto teológico.

En 1270 Tomás de Aquino finaliza la primera parte de la Suma Teológica. En 1272 concluye la segunda parte. Al año siguiente es profesor en Nápoles. Realiza la tercera parte de la Suma acerca de "Cristo", "Los Sacramentos" y la "Gloria divina". En marzo de 1273 tiene un profundo éxtasis. Llora por varias horas pero no dice lo que experimentó. Trabaja largas horas y pasa otras frente al crucifijo. El 6 de diciembre tiene otra experiencia mística luego de la cual archiva sus documentos definitivamente. Solo dijo que ya no podía seguir escribiendo. Su colaborador Fray Reginaldo de Piperno (1230 - 1290) le escuchó decir que luego de esa experiencia con Dios le parecía innecesario todo y cuanto había escrito en toda su vida. Gregorio X lo convoca al concilio de Lyon. Tomás inició el trayecto pero el 7 de marzo de 1274 se enferma y fallece en el monasterio cisterciense de Fossanova, entre Nápoles y Roma. Tenía entonces 49 años.

\section{Panorama histórico e ideológico de Tomás de Aquino}

San Agustín de Hipona (354 - 430) representa la última etapa del Imperio Romano que se fue disolviendo progresivamente. Durante el siglo IV los germanos y los bárbaros no conservaron los textos griegos de filosofía que fueron preservados en las abadías. Durante el siglo VI se funda el Islam que se expande velozmente. En su paso por el sur de Egipto, los mahometanos conocen la gran biblioteca de Alejandría. Allí se encontraban todos los textos de Aristóteles y los tradujeron al árabe, sobre todo los textos de lógica. 
Entre los representantes más importantes del aristotelismo islámico tenemos a Avicena y Averroes quienes estudiaron y tradujeron los textos de Aristóteles. Los dos reconocen que hay una verdad revelada por la razón y una verdad revelada por la fe.

\section{Para Avicena las dos verdades} coinciden.

Si la razón llega a una verdad diferente a Dios es que se está haciendo mal uso de la razón. La verdad revelada tiene primacía sobre la verdad de la razón.

\section{Lo mismo dirá Santo Tomás:}

"La filosofía es la criada de la teología". La razón está al servicio de la fe.

Para Averroes la verdad alcanzada por la razón y la verdad revelada por la fe tienen objetivos distintos. Afirma que la verdad alcanzada por la razón sostiene el conocimiento científico; mientras que la verdad revelada por la fe sirve para aumentar nuestra fe.

Siglo XII se funda la universidad de París. La tradición recogía con agrado los textos de San Agustín con su influjo platónico. Se discute, en cambio si es pertinente insertar los textos de Aristóteles debido a que los textos de lógica descubiertos por los árabes entraban en contradicción con la visión del mundo de San Agustín.

El pensamiento de San Agustín no encuentra diferencia notoria entre filosofía y teología. En su tiempo, la filosofía era un modo de vida (Epicúreos, estoicos, etc.) más que una postura teórica. El obispo de Hipona quiere hacer de la teología también un modo de vida. En cambio, para San Agustín el cristianismo era la filosofía verdadera y la forma de vida que conducía a la verdadera felicidad. La felicidad falsa la traían las satisfacciones momentáneas (lujuria, codicia, lucro y honores). No se trata de un conocimiento científico como el que pretende Aristóteles. Había entonces un divorcio entre ciencia y la dupla teología / filosofía. Por esta razón, las ideas de Aristóteles no eran del todo bienvenidas. Su filosofía debía destinarse al mundo sensible que requiere del conocimiento exacto. El pensamiento agustiniano crea una diferencia entre:

¿Qué diferencia nos trae Aristóteles?

\section{Ciencia}

Mundo sensible

Conocimiento exacto del mundo.

\section{Filosofía y Teología}

Formas de vida

No es conocimiento exacto del mundo.

Textos de Lógica, Política, Ética y Física. Su teoría afecta el modo tradicional de exponer las creencias católicas por lo siguiente:

1. Para el filósofo griego Dios es el "motor inmóvil" que no es como el "Dios creador" del judeo-cristianismo porque solo es inteligencia y no tiene deseos ni voluntad. Un Dios con voluntad implica movimiento hacia algo. Tal actividad implicaría una necesidad previa que promueve el deseo. Desear significa una carencia que debe ser satisfecha y por ello un Dios con deseos sería inviable.

2. Trae una herramienta lógica que permite demostrar la verdad de ciertas afirmaciones: el silogismo demostrativo.

El silogismo demostrativo consta de tres proposiciones. Las dos primeras son premisas verdaderas y la tercera premisa concluye en función de las anteriores:

1) Premisa Mayor. Conjunto de todos los individuos de un universo: "Todos los hombres son mortales".

2) Premisa menor. Individuo particular que forma parte del universo: "Sócrates es hombre".

3) Conclusión: "Sócrates es mortal". 
El silogismo aplicado a la teología convierte a la teología en ciencia. Rompe con la visión agustiniana de la teología. Alberto Magno, maestro de Tomás de Aquino, traduce y elabora los textos de Aristóteles. Tomás de Aquino es el artífice de la gran síntesis. Realiza una fusión del cristianismo de la época con el razonamiento de Aristóteles que es identificado en la ciencia de las cuatro causas, la teoría de la sustancia como también del tratado acerca de la potencia y del acto. El aquinate adopta entonces la posición metafísica de Avicena cuando distingue entre "esencia" y "existencia"; para referirse a Aristóteles le llama "El Filósofo" y para referirse a Pablo dice "El Apóstol". Surge la oposición con el averroísmo latino que entonces lideraba Siger de Brabant.

En el siglo XIII habían cambiado las cosas pero la filosofía todavía recibía mayor influjo del pensamiento agustiniano. La presencia de Aristóteles crea una división en la teología católica de aquél tiempo. Los franciscanos, liderados por San Buenaventura, son ideológicamente agustinianos que se oponen al estudio de Aristóteles. Por el lado de los Dominicos, tenemos a San Alberto Magno y Santo Tomás de Aquino. Era problemático para un católico aceptar las ideas de Aristóteles porque viene de manos de "los paganos" del Islam y además Aristóteles era otro pagano. En París se condenan las ideas de Aristóteles y por ende las ideas de Tomás de Aquino. Luego de un tiempo las cosas cambian y se restituye su pensamiento.

En conclusión tenemos tres posturas en esta etapa del medioevo:

1) No aceptar el pensamiento de Aristóteles.

2) Aceptar las ideas de Avicena. (Santo Tomás va por esta línea).

3) Aceptar las ideas de Averroes.

Era un momento que ahora podemos considerar decisivo para el desarrollo de la teología católica. Tomás de Aquino junto a su maestro Alberto Magno tienen la tarea de vencer las barreras ideológicas planteadas por la tradición platónico-agustiniana que estaban fuertemente arraigadas en el pensamiento teológico de entonces. El proyecto consistió en cristianizar el pensamiento aristotélico original y el aporte de la ciencia greco-arábiga integrando algunos elementos de la tradición platónico-agustiniana (Guerrero, 1996). Tomás de Aquino aclaró las ideas ya plasmadas por su maestro e integró los diversos elementos que conformaban el pensamiento del siglo XIII.

\section{Pensamiento filosófico - teológico}

El aquinate era ya cristiano antes de ingresar en el tema aristotélico y metafísico. Su sistema de creencias tenía como eje la creencia en Dios la cual no había sido resultado de una ideología sustentada en la filosofía. Por lo tanto, él cuando propone argumentos en favor de la existencia de Dios, no tiene por meta convencerse filosóficamente de la existencia del mismo. La realidad de Dios es ya un presupuesto inconsciente en el autor de la Suma Teológica. Él tampoco está luchando contra la corriente de su contexto socio histórico dentro del cual no se podía prescindir de Dios como razón de ser de todas las cosas. Se trata entonces de un asunto lógico. Si estamos tratando acerca de Dios es necesario ir por las bases de esa creencia. La pregunta por Dios, sin embargo desde una postura filosófica permite la posibilidad de la duda acerca de su existencia, y Santo Tomás fue honesto como metafísico al plantear los cuestionamientos contrarios al teísmo para luego resolverlos. Más allá de eso, la existencia de Dios no se muestra evidente y por lo tanto requiere demostración.

Para entonces ya había formas simples y no por ello irrelevantes con argumentos favorables acerca de la existencia de Dios. Conocemos que San Anselmo y San Buenaventura tenían postulados interesantes al respecto. Insuficientes desde la perspectiva de Santo Tomás. La "perfección", y por otra parte, la "felicidad" eran todavía elementos discutibles dentro del contexto en el cual aquellos, no sin maestría, los ubican para sustentar sus convicciones. El aquinate va por una vía distinta. Parte de la experiencia sensible, distancias guardadas con el empirismo moderno, y siendo consciente que la estructura 
cognoscente es compuesta: no es un espíritu puro el que conoce sino un ser que en los fundamentos de su conocimiento es psicofísico. La experiencia de Dios es terrestre. Por más que se trate una experiencia trascendente se trata de una experiencia ubicada y siempre desde una perspectiva. Nuestra apuesta por la existencia de Dios tiene que ser aceptada por un sujeto que está "sujetado" en varios sentidos por sus experiencias sensibles. La atmósfera aristotélica se pone en evidencia. Sin embargo no se trata de creer que la vía de la argumentación racional sea el único modo de conocimiento. El conocimiento místicoreligioso, por ejemplo, es un acceso más próximo a la creencia en Dios y que presenta menos problemas que el conocimiento sobre la base de argumentos racionales.

A continuación expongo el texto acerca del tratado de la existencia de Dios en el cual Santo Tomás expone las cinco vías para la demostración de su existencia. Tomado de la Suma Teológica, cuestión 2, artículos 2 y 3 (Tomás de Aquino, 2001 [1], págs. 109-113) Luego comentaré cada vía que responde a la cuestión fundamental de estos artículos:

\section{CUESTIÓN 2}

\section{SOBRE LA EXISTENCIA DE DIOS}

\section{ARTÍCULO 2}

\section{La existencia de Dios, ¿es o no demostrable?}

Objeciones por las que parece que Dios no es demostrable.

1. La existencia de Dios es artículo de fe. Pero los contenidos de fe no son demostrables, puesto que la demostración convierte algo en evidente, en cambio la fe trata de lo no evidente, como dice el Apóstol en Heb 2, 1. Por lo tanto, la existencia de Dios no es demostrable.

2. Más aún. La base de la demostración está en lo que es. Pero de Dios no podemos saber qué es. Sino sólo qué no es, como dice el Damasceno. Por lo tanto, no podemos demostrar la existencia de Dios.

3. Todavía más. Si se demostrase la existencia de Dios, no sería más que por sus efectos. Pero sus efectos no son proporcionales a Él, en cuanto a que los efectos son finitos y Él es infinito; y lo finito no es proporcional a lo infinito. Como quiera, pues, que la causa no puede demostrarse a partir de los efectos que no le son proporcionales, parece que la existencia de Dios no puede ser demostrada.

En cambio está lo que dice el Apóstol en Rom 1, 20: Lo invisible de Dios se hace comprensible y visible por lo creado. Pero esto no sería posible a no ser que por lo creado pudiera ser demostrada la existencia de Dios, ya que lo primero que hay que saber de una cosa es si existe.

Solución. Hay que decir: Toda demostración es doble. Una, por la causa, que es absolutamente previa a cualquier cosa. Se la llama: a causa de. Otra, por el efecto, que es lo primero con lo que nos encontramos; pues el efecto se nos presenta como más evidente que la causa, y por el efecto llegamos a conocer la causa. Se la llama: porque. Por cualquier efecto puede ser demostrada su causa (siempre que los efectos de la causa se nos presenten como más evidentes): porque, como quiera que los efectos dependen de la causa, dado el efecto, necesariamente antes se ha dado la causa. De donde se deduce que la existencia de Dios, aun cuando en sí misma no se nos presenta como evidente, en cambio sí es demostrable con los efectos con que nos encontramos.

\section{Respuestas a las objeciones:}

1. A la primera hay que decir: La existencia de Dios y otras verdades que de Él pueden ser conocidas por la razón natural, tal como dice Rom 1 , 19 , no son artículos de fe conocer por discurso natural, como dice el Apóstol, no son artículos de fe, sino preámbulos a tales artículos. Pues la fe presupone 
el conocimiento natural, como la gracia presupone la naturaleza y la perfección lo perfectible. Sin embargo, nada impide que lo que en sí mismo es demostrable y comprensible, sea tenido como creíble por quien no llega a comprender la demostración.

2. A la segunda hay que decir: Cuando se demuestra la causa por el efecto, es necesario usar el efecto como definición de la causa, y esto sucede particularmente cuando se trata de Dios. La razón es porque en este caso para probar la existencia de la causa. Esto es así sobre todo por lo que respecta a Dios. Porque para probar que algo existe, es necesario tomar como base lo que significa el nombre, no lo que es; ya que la pregunta qué es presupone otra: si existe. Los nombres dados a Dios se fundamentan en los efectos, como probaremos más adelante (...). De ahí que, demostrando por el efecto la existencia de Dios, podamos tomar como base lo que significa este nombre Dios.

3. A la tercera hay que decir: Por efectos no proporcionales a la causa no se puede tener un conocimiento exacto de la causa. Sin embargo, por cualquier efecto puede ser demostrada claramente que la causa existe (...). Así por efectos divinos puede ser demostrada la existencia de Dios, aun cuando por los efectos no podamos llegar a tener un conocimiento exacto de cómo es Él a sí mismo.

\section{ARTÍ́CULO 3}

\section{¿Existe o no existe Dios?}

Objeciones: por las que parece que Dios no existe:

1. Si uno de los contrarios es infinito, el otro queda totalmente anulado. Esto es lo que sucede con el nombre Dios al darle el significado de bien absoluto. Pues si existiese Dios, no existiría ningún mal. Pero el mal se da en el mundo. Pero el mal se da en el mundo. Por lo tanto Dios no existe.

2. Más aún. Lo que encuentra su razón de ser en pocos principios, no se busca en muchos. Parece que todo lo que existe en el mundo y supuesto que Dios no existe, encuentra su razón de ser en otros principios; pues lo que es natural encuentra su principio en la naturaleza; lo que es intencionado lo encuentra en la razón y voluntad humanas. Así, pues, no hay necesidad alguna de acudir a la existencia de Dios.

En cambio está lo que se dice en Éxodo 3, 14 de la persona de Dios: Yo existo.

Solución. Hay que decir: La existencia de Dios puede ser probada de cinco maneras distintas.

La primera (vía) y más clara es la que se deduce en el movimiento. Pues es cierto, y lo perciben los sentidos, que en este mundo hay movimiento. $Y$ todo lo que se mueve es movido por otro. De hecho nada se mueve a no ser que en, cuanto potencia, esté orientado a aquello por lo que se mueve. Por su parte, quien mueve está en acto. Pues mover no es más que pasar de la potencia al acto. La potencia no puede pasar a acto más que por quien está en acto. Ejemplo: el fuego, en acto caliente, hace que la madera, en potencia caliente pase a caliente en acto. De este modo la mueve y cambia. Pero no es posible que una cosa sea lo mismo simultáneamente en potencia y en acto; sólo lo puede ser a algo distinto. Ejemplo: Lo que es caliente en acto, no puede ser al mismo tiempo caliente en potencia, pero sí puede ser en potencia frío. Igualmente, es imposible que algo mueva y sea movido al mismo tiempo, o que se mueva a sí mismo. Todo lo que se mueve necesita ser movido por otro, y éste por otro. Este proceder no se puede llevar indefinidamente, porque no se llegaría al primero que mueve, y así no habría motor alguno pues los motores intermedios no mueven más que por ser movidos por el primer motor. Ejemplo: Un 
bastón no mueve nada si no es movido por la mano. Por lo tanto, es necesario llegar a aquel primer motor al que nadie mueve. En éste, todos reconocen a Dios.

La segunda (vía) es la que se deduce de la causa eficiente. Pues nos encontramos que en el mundo sensible hay un orden de causas eficientes. Sin embargo, no encontramos, ni es posible, que algo sea causa eficiente de sí mismo, pues sería anterior a sí mismo, cosa imposible. En las causas eficientes no es posible proceder indefinidamente porque en todas las causas eficientes hay orden: la primera es de causa intermedia; y ésta, sea una o múltiple, lo es de la última. Puesto que, si se quita la causa, desaparece el efecto, si en el orden de las causas eficientes no existiera la primera, no se daría tampoco ni la última ni la intermedia. Si en las causas eficientes llevásemos hasta el infinito este proceder, no existiría la primera causa eficiente; en consecuencia no habría efecto último ni causa intermedia; y esto es absolutamente falso. Por lo tanto, es necesario admitir una causa eficiente primera. Todos la llaman Dios.

La tercera (vía) es la que se deduce a partir $\mathrm{de}$ lo posible y de lo necesario. $\mathrm{Y}$ dice: Encontramos que las cosas pueden existir o no existir, pues pueden ser producidas o destruidas, y consecuentemente es posible que existan o que no existan. Es imposible que las cosas sometidas a tal posibilidad existan siempre, pues lo que lleva en sí mismo la posibilidad de no existir, en un tiempo no existió. Sí pues, todas las cosas llevan en sí mismas la posibilidad de no existir, hubo un tiempo en que nada existió. Pero si esto es verdad, tampoco ahora existiría nada, puesto que lo que no existe no empieza a existir más que por algo que ya existe. $\mathrm{Si}$, pues, nada existía, es imposible que algo empezara a existir; en consecuencia, nada existiría; y esto es absolutamente falso. Luego los seres son sólo posibilidad; sino que es preciso algún ser necesario. Todo ser necesario encuentra su necesidad en otro, o no la tiene. Por otra parte, no es posible que en los seres necesarios se busque la causa de su necesidad llevando este proceder indefinidamente, como quedó probado al tratar las causas eficientes (núm. 2). Por lo tanto, es preciso admitir algo que sea absolutamente necesario, cuya causa de su necesidad no esté en otro, sino que él sea la causa de la necesidad de los demás. Todos le dicen Dios.

La cuarta (vía) se deduce de la jerarquía de valores que encontramos en las cosas. Pues nos encontramos que la bondad, la veracidad, la nobleza y otros valores se dan en las cosas. En unas más y en otras menos. Pero este más y este menos se dice de las cosas en cuanto que se aproximan más o menos a lo máximo. Así, caliente se dice de aquello que se aproxima más al máximo calor. Hay algo, por tanto, que es muy verás, muy bueno, muy noble; $y$, en consecuencia, es el máximo ser; pues las cosas que son absolutamente verdaderas, son seres máximos, como se dice en II Metaphys. Como quiera que en cualquier género - así el fuego, que es el máximo calor, es causa de todos los calores, como se explica en el mismo libro -, del mismo modo hay algo que en todos los seres es a causa de su existir, de su bondad, de cualquier otra perfección. Le llamamos Dios.

La quinta (vía) se deduce a partir del ordenamiento de las cosas. Pues vemos que hay cosas que no tienen conocimiento, como son los cuerpos naturales, y que obran por un fin. Esto se puede comprobar observando cómo siempre o a menudo obran igual para conseguir lo mejor. De donde se deduce que, para alcanzar su objetivo, no obran al azar, sino intencionadamente. Las cosas que no tienen conocimiento no tienden al fin sin ser dirigidas por alguien con conocimiento e inteligencia, como la flecha por el arquero. Por lo tanto, hay alguien inteligente por el que todas las cosas son dirigidas al fin. Le llamamos Dios.

\section{Respuesta a las objeciones:}

1. A la primera hay que decir: Escribe Agustín en el Enchiridio: Dios, por ser el bien sumo, de ninguna manera permitiría que hubiera algún tipo de mal en sus obras, a no ser que, por ser omnipotente y bueno, del mal sacara un bien. Esto pertenece a la infinita bondad de Dios, que puede permitir el mal para sacar de él algún bien. 
2. A la segunda hay que decir: Como la naturaleza obra por un determinado fin a partir de la dirección de alguien superior, es necesario reducirlo a alguna causa superior que no sea la razón y la voluntad humanas; puesto que éstas son mudables y perfectibles. Es preciso que todo lo sometido a cambio y posibilidad sea reducido a algún primer principio inmutable y absolutamente necesario, tal como ha sido demostrado.

\section{Comentario para cada vía de argumentación filosófica:}

Santo Tomás nos muestra las cinco vías que parten de hechos de la experiencia:

1) La experiencia del movimiento, en sentido local, cuantitativo o cualitativo (Fraile, 2005), es el trayecto de la potencia al acto que se convierte en inicio de argumento porque se percibe como una cosa que es movida por otra. Se trata del paso de lo posible a su realización. Las cosas del mundo reciben influencia y quedan "alteradas" por otros objetos, o como dirá Tomás: "todo lo que se mueve es movido por otro". Hay algo previo siempre a todo lo modificado debido a que el trayecto de lo potencial hacia el acto, que implica ya nueva inmovilidad, no puede realizarla el móvil por su propia cuenta. Lo móvil no puede ser inmóvil al mismo tiempo. Algo anterior, que es inmóvil, lo mueve. Ha de ser agente primero en orden, no en el sentido temporal sino ontológico (Copleston, 1960), el motor inmóvil que es Dios.

2) El conocimiento de las causas eficientes invita a pensar que existe condición de posibilidad para cada cosa. Las cosas no se pueden causar a sí mismas. Hay algo que antecede a lo otro en el orden del ser y de la operación (Fraile, 2005). No se trata de una causalidad secuencial o en cadena de cosas que provocan inmediatamente otras sino en sentido de subordinación. Hay cosas que se mueven con independencia de aquellas que les dieron origen. Se trata entonces de causas eficientes que señalan dependencia jerárquica mas no encadenada como sería fácil entender hoy cualquier relación causal que sólo nos llevaría al permanente retorno sin momento inicial. Tomás pregunta acerca de un inicio en sentido jerárquico y se contesta que hay una causa que es condición de posibilidad para todo lo demás que es Dios.

3) A Dios se lo puede empezar a conocer por medio de la experiencia de lo corruptible y finito. Hay antes algo eterno que permanece y crea las cosas que pueden dejar de existir. Lo que tuvo origen tiene en si la posibilidad de dejar de ser y si no existió antes no puede darse vida a sí misma. Para la usanza medieval se trata de seres "posibles" y para la traducción contemporánea de lo mismo adoptamos el término "contingente" (Copleston, 1960) que significa aquello que existe luego de no haber existido y que puede dejar de existir luego de haber existido (Fraile, 2005). De ello se deduce que tiene que haber algo anterior que genere a los seres contingentes y aquello es Dios.

4) Observamos el grado de perfección distinto en unos seres y en otros. No se trata de perfecciones esenciales (la nube, el caballo y el hombre no son ni más ni menos que nube, caballo $y$ hombre). Se trata de perfecciones análogas (Fraile, 2005) que pueden ser trascendentales como el ser, la bondad, la verdad y la belleza) o no trascendentales como la vida, el entender y el querer. Esto invita a suponer que hay superioridad en algunos seres por su grado de perfección. Una referencia de esta perfección es la bondad como la realización del sumo Bien al que nos hace referencia la filosofía platónica. Los seres más próximos a la idea del Bien son superiores en grado de perfección y hay uno que es considerado el ser Supremo o Ser absoluto trascendente que encierra en 
sí mismo la plenitud de todo bien y ese es Dios.

5) Se observa actividad teleológica en los seres que carecen de conocimiento. Cada ser, a pesar de no ser pensante actúa por un fin en función de su naturaleza. La mirada actual de la teleología en las cosas de Tomás de Aquino puede fácilmente inducirnos a la falsa idea de una visión poco científica de la realidad. La teleología que hay en los seres no pertenece al orden de relaciones en el sentido del gorrión que se come a los insectos para luego liberar a los hombres de las plagas, sino en el sentido de aquello que carece de conocimiento y que está ordenado o que "se articula con" los otros seres y cosas de la realidad. Tomás hoy habría usado como ejemplo la teoría evolucionista como hipótesis válida para aclarar esta vía (Copleston, 1960). Se hace necesario una inteligencia que grabe el camino a seguir en estos seres. Por ello se deduce que debe haber un Ser que tenga conocimiento que otorga sentido a dicha actividad que percibimos como intencional y ese es Dios.

Tal como lo entiende Copleston (1960), hay cierta mesura en las expresiones del aquinate a la hora de plasmar sus argumentos en favor de la existencia de Dios en forma de relaciones causales. Por ejemplo en la vía tercera dice: "Encontramos que las cosas pueden existir o no existir..." (Tomás de Aquino, 2001 [1], pág. 112). No dice: "Encontramos que las cosas existen"; y en la misma página, cuando aborda la vía quinta dice: “... como son los cuerpos naturales, y que obran por un fin. Esto se puede comprobar observando cómo siempre, o a menudo, obran igual para conseguir lo mejor". Tomás de Aquino está lejos de presentar hipótesis empíricas al estilo de la ciencia de nuestro tiempo. Si fuese así podríamos cuestionar casi de inmediato lo que nos está proponiendo en cada vía. Santo Tomás encuentra relación de hechos en el sentido de relación a una causa primera que es trascendente.
El pensamiento de Santo Tomás no es ingenuo respecto a lo que hoy llamaríamos rigor científico. El aquinate utilizó las herramientas de la ciencia de su época y según esos lenguajes describió hechos que permitieran acceder por la vía racional el conocimiento de Dios. Demostraciones acerca de la existencia de un ser supremo no es tarea libre de cuestionamientos y el autor de la Suma Teológica lo tenía claro:

Es verdad que el santo tenía confianza en el poder de la razón humana para llegar al conocimiento de la existencia de Dios; y no consideraba que sus argumentos necesitaran apoyarse en un atractivo retórico o sentimental. En la Suma teológica, escrita para los "novicios" en teología, asienta sus argumentos de forma sobria y quizá desconcertantemente impersonal. Pero de ahí no podemos concluir legítimamente que era muy fácil para el hombre el llegar al conocimiento de la existencia de Dios por medio de la sola reflexión filosófica (...), afirma explícitamente lo contrario. Se daba muy bien cuenta de que en la vida humana hay otros factores, además de la reflexión filosófica, que ejercen una gran influencia (Copleston, 1960, p, 130)

\section{CONCLUSIONES}

La vida del santo dominico muestra la situación que le tocó vivir no exenta de contrariedades y conflictos familiares en una época en la cual era normal la injerencia de las figuras significativas en decisiones vitales de los hijos. La situación familiar aquí es el reflejo de la atmósfera ideológica imperante. El mundo del medioevo sostenía su creencia en Dios a partir de una jerarquía religiosa de poderoso influjo sobre aquello que se debía creer y por qué camino. Tomás decide hacerse monje dominico por vocación en vez de hacer carrera eclesiástica por ocasión, como era el deseo de la familia. El joven teólogo realizará la misma operación a nivel intelectual reconociendo la necesidad de hacer teología de la mano de una filosofía peligrosa para los intereses de la jerarquía 
católica de entonces. Por ello también tuvo que enfrentarse a un sector importante de la intelectualidad seglar y religiosa en el ámbito ideológico. Tiene que luchar contra poderosos prejuicios respecto al pensamiento aristotélico y al prejuicio contra los "infieles" islámicos que se habían adelantado a Occidente en el desarrollo filosófico y matemático.

Por los datos que nos llegan de la vida personal de Santo Tomás es posible entrever cierta correspondencia de su historia individual con su actividad intelectual como filósofo y teólogo. Lo que sí queda claro es la humildad y lucidez de este pensador que finalmente lleva adelante una de las empresas mejor logradas de la teología católica. Tomás, sin embargo, pasará de la comprensión intelectual de Dios al conocimiento místico-religioso. Cuando se cierra la puerta filosófico-teológica y se establece contacto íntimo con Dios, el discurso anterior no queda despreciado, solo que es mirado sin anhelo. Lo que no es asunto espiritual queda suspendido. Una experiencia "cara a cara" es un momento en el cual se unen posibilidades divergentes de actividad y pasividad en la cual uno, sin dejar de ser uno mismo, experimenta plena confianza y el ser-uno (sí mismo personal) se deja sostener por el Ser mismo que pretendió demostrar con palabras en el registro humano de la teología. Este encuentro místico le permitirá escribir el epílogo más importante de la Suma teológica que no fue precisamente su tratado De los Novísimos. En cambio, fue el silencio de Tomás ante la grandeza de aquello que, a punta de razón natural, intentó bosquejar acompañado de la revelación bíblica. Todo ello da cuenta de la verdadera dimensión de su sinceridad como teólogo y como persona.

Su aporte de las cinco vías de la existencia de Dios es buen testimonio de su profundidad filosófica que, salvo algunas aclaraciones, tiene vigencia en la discusión en el sentido metafísico. En el recuento de las vías que la razón natural ofrece para la creencia en Dios, Santo Tomás apela al movimiento, a la causa eficiente, a seres finitos (contingentes), a seres relativamente perfectos $y$ al orden del mundo para dar cuenta del Ser inmutable (motor inmóvil), Causa primera universal, Ser necesario, Valor supremo e Inteligencia ordenadora de todas las cosas. Este trabajo del intelecto sintetiza los esfuerzos de la época por la demostración de la existencia de un ser previo a todo lo que es finito. Tomás añade algo importante para abrir las puertas a la autonomía de la razón: es necesario ingresar a la demostración desde la experiencia sensible; todo ello desde premisas que no pretenden describir realidades definitivas sino hechos desde los cuales es más fácil argumentar acerca de aquello que está fuera del alcance de nuestros sentidos. 


\section{REFERENCIAS}

Copleston, F. C. (1960) El pensamiento de Santo Tomás de Aquino. México - Buenos Aires: FCE.

Copleston, F. C. (1994) Historia de la filosofía. Tomo 2 De Agustín a Escoto. Barcelona: Ariel.

Fishl, J. (1984) Manual de historia de la filosofía. Barcelona: Herder.

Fraile, G. (2005) Historia de la Filosofía (II 2. ${ }^{\circ}$ ) Filosofía judía y musulmana. Alta escolástica: desarrollo y decadencia. Madrid: Biblioteca de Autores Cristianos.

Guerrero, R. (1996) Historia de la filosofía medieval. Madrid: Ediciones Akal.

Llorca, B. García-Villoslada, R. y Laboa, J. M. (2009) Historia de la Iglesia católica. Tomo 2: Edad Media. La cristiandad en el mundo europeo y feudal. Madrid: Biblioteca de Autores Cristianos.

Martínez Lorca, A. (2011) Introducción a la filosofía medieval. Madrid: Alianza Editorial.

Reale, G. y Antiseri, D. (2010) Historia de la filosofía. Tomo 2: Patrística y Escolástica. Barcelona: Herder.

Thai-Hop, P. (1988) Tomás de Aquino. Teólogo militante. Chimbote: IPEP

Tomás de Aquino (2001) Suma teológica. Tomo 1. Madrid: Biblioteca de Autores Cristianos.

Fecha de recepción: 23 de marzo 2015

Fecha de aceptación: 29 de abril 2015 